\title{
Correction to: An Approach to Obesity Management for Gastroenterologists and Hepatologists
}

Jessica Briscoe, $M D^{1, *}$

Monica Saumoy, MD MS ${ }^{2}$

Octavia Pickett-Blakely, MD, MHS

\author{
Address \\ *,1Division of Gastroenterology and Hepatology, Temple University Hospital, 3401 \\ N. Broad Street, Philadelphia, PA, 19140, USA \\ Email: Jessica.briscoe@tuhs.temple.edu \\ ${ }^{2}$ Division of Gastroenterology and Hepatology, University of Pennsylvania Perel- \\ man School of Medicine, Philadelphia, PA, USA
}

Published online: 7 January 2020

(C) Springer Science+Business Media, LLC, part of Springer Nature 2020

The online version of the original article can be found at https://doi.org/10.1007/s11938-019-00250-5

\section{Correction to: Curr Treat Options Gastro}

$$
\text { https://doi.org/10.1007/s11938-019-00250-5 }
$$

The original article unfortunately contained a mistake. Rights and permission statements for Table 1 and Figure 1 were not captured.

The original version has been corrected. 